ORIGINAL ARTICLE

\title{
A longitudinal study on the ammonia threshold in junior cyclists
}

\section{Y Yuan, K-M Chan}

See end of article for authors' affiliations .....................

Correspondence to: Dr Yuan, Hong Kong Sports Development Board, Sports Institute, Yuen Wo Road, Shatin, Hong Kong; yvonney@ hksdb.org.hk

Accepted 26 March 2003
Objectives: To identify the effect of a one year non-specific training programme on the ammonia threshold of a group of junior cyclists and to correlate ammonia threshold with other common physiological variables.

Methods: The cyclists performed tests at three time points (T1, T2, T3) during the year. Follow up tests were conducted every six months after the original test. Ammonia threshold was obtained from a graded exercise with four minute steps.

Results: The relatively non-specific one year training programme was effective in inducing an increase in peak $\mathrm{VO}_{2}(60.6(5.9), 65.9(7.4)$, and $64.6(6.5) \mathrm{ml} / \mathrm{min} / \mathrm{kg}$ at $\mathrm{T} 1, \mathrm{~T} 2$, and $\mathrm{T} 3$ respectively) and endurance time (18.3 (4.5), 20.1 (5.2), and 27.0 (6.1) minutes at T1, T2, and T3 respectively), but was not effective for the sprint related variables. Ammonia threshold, together with lactate threshold and ventilatory threshold, was not significantly different at the three test times. Only endurance time correlated significantly with ammonia threshold $(r=0.915, p=0.001)$.

Conclusions: The findings suggest that a relatively non-specific one year training programme does not modify the ammonia threshold of junior cyclists. The significant correlation between ammonia threshold and endurance time further confirms that ammonia threshold is a measure of the ability to sustain exercise at submaximal intensities.
$\mathrm{E}$ xercise of various mode, intensity, and duration has been shown to induce an increase in blood ammonia concentration. ${ }^{1-3}$ The major sources of exercise ammonia are adenosine monophosphate (AMP) deaminase and catabolism of branched chain amino acids. During high intensity exercise, ammonia originates mainly from the deamination of AMP. ${ }^{4}$ However, during prolonged submaximal exercise, the oxidation of amino acids becomes an increasingly important source of ammonia production. ${ }^{3}$ Ammonia produced during exercise alters neuromuscular activity, may contribute to local muscle fatigue, and can also have detrimental effects on the central nervous system when it reaches the brain. ${ }^{5}$ As suggested by Mutch and Banister, ${ }^{5}$ a reduction in blood ammonia during exercise may increase a person's capacity for exhaustive exercise.

Exercise ammonia concentration is also sensitive to training. Both sprint training ${ }^{6}$ and endurance training ${ }^{7}$ have been found to reduce the exercise induced increases in blood ammonia concentration. The effect of training on ammonia response has been widely studied in adults and for training programmes that lasted for six to eight weeks. ${ }^{7-9}$ The effect of long term training on ammonia production in adolescent athletes is currently inconclusive. Previous studies ${ }^{6}{ }^{10}$ have compared ammonia response in trained and untrained children, and exercise ammonia was lower in the untrained children. However, there has been a lack of a direct comparison of ammonia response of children before and after training.

When the ammonia response of children was compared with that in adults, the increase in ammonia during maximal exercise in children was lower than that in adults. ${ }^{10}$ The lower ammonia response in children agrees with the reported lower anaerobic potential of skeletal muscles ${ }^{11}$ and the smaller oxygen deficit resulting from the faster rate of oxygen uptake at the onset of exercise in children ${ }^{12}$. Nazar et al ${ }^{10}$ also speculated that children may be able to remove ammonia in the bloodstream more effectively than adults. Together with other findings on the lower maximal anaerobic power and capacity of children, ${ }^{13}{ }^{14}$ there is a need to investigate if training can change the ammonia response to exercise in children.

During progressive incremental exercise, blood ammonia concentration increases with exercise intensity in such a way that a threshold value exists. ${ }^{15}$ The ammonia threshold, obtained from a four minute step incremental exercise, was found to be sensitive to endurance training, but not sprint training. ${ }^{16}$ It was also found to correlate significantly with the lactate threshold, ventilatory threshold, and endurance time. ${ }^{16}$ It appears that the ammonia threshold may indicate the ability to sustain submaximal exercise. ${ }^{16}$

We therefore investigated the effect of long term training (one year) on the ammonia threshold in a group of junior cyclists. Their physiological profiles, including the ammonia threshold obtained from a progressive incremental exercise, were followed over one year of systematic training consisting of not less than five days a week and averaging three hours a day. The correlation of ammonia threshold with other common physiological variables, including lactate threshold, ventilatory threshold, peak oxygen uptake, and sprinting capacity related variables, was also studied.

\section{MATERIALS AND METHODS}

Eight junior cyclists were recruited to the study. Table 1 summarises their physical characteristics. They had joined the Hong Kong Sports Development Board's scholarship programme and had participated in organised training for less than 18 months. They had received a full explanation of the procedure and volunteered for the study. The Hong Kong Sports Development Board ethically approved all procedures.

The effects of long term training were assessed by repeating the same test battery three times ( $\mathrm{T} 1, \mathrm{~T} 2$, and $\mathrm{T} 3$ ) within the year. The training programme during the test period emphasised the general development of the cyclists, and there were no major competitions to peak for. The 
Table 1 Physical characteristics of the subjects at the three test time points

\begin{tabular}{lllllll}
\hline & Age (years) & Height $(\mathrm{cm})$ & Weight $(\mathbf{k g})$ & \% body fat & Lean mass $(\mathbf{k g})$ & Peak Vo $\mathbf{~}(\mathrm{ml} / \mathbf{k g} / \mathbf{m i n})$ \\
\hline T1 & $16.1(1.0)$ & $170.6(5.5)$ & $59.1(4.9)$ & $5.8(2.1)$ & $56.1(3.5)$ & $60.6(5.9)$ \\
T2 & $16.6(1.0)$ & $172.0(5.2)$ & $59.4(5.2)$ & $6.0(1.6)$ & $55.8(4.1)$ & $65.9(7.3)$ \\
T3 & $17.1(1.0)$ & $172.8(5.5)$ & $60.8(4.8)$ & $5.7(1.8)$ & $57.3(4.0)$ & $64.6(6.5)$ \\
\hline
\end{tabular}

Values are mean (SD). Percentage body fat was estimated from age and sum of chest, abdomen, and thigh skinfolds. $^{25}$

cyclists spent not less than five days a week and an average of three hours a day in training. The three test times were evenly separated from each other by six months. The cyclists were instructed to consume a similar diet with high carbohydrate content on the day before testing. The test battery consisted of four tests: peak $\mathrm{VO}_{2}$ test; four minute step graded exercise; sprint test; and endurance test. Each cyclist performed the tests in random order except the peak $\mathrm{VO}_{2}$ test, which always preceded the endurance test. All four tests were completed within seven days, and at least one day of rest was allowed between tests.

\section{Test protocols}

All tests, except the sprint tests, were performed on the cyclists' own bike mounted on a Cateye bike simulator (CS 1000; Cateye Co, Ltd, Osaka, Japan). Gear ratio and cadence were not predetermined, and the athletes were required to keep the power output as close as possible to the assigned value during all the tests. Before each test, participants underwent a 10 minute standard warm up followed by five minutes of seated rest.

\section{Peak $\mathrm{Vo}_{2}$ test}

All participants performed a peak $\mathrm{VO}_{2}$ test with a metabolic cart (Vmax29; SensorMedics, Yorba Linda, California, USA), which had been calibrated according to the guidelines provided by the manufacturer. During the test, power output was increased by $20-25 \mathrm{~W}$ per minute. The initial workload and increment were chosen according to the subject's exercise capacity. All peak $\mathrm{VO}_{2}$ tests were completed in 8-12 minutes.

Peak $\mathrm{VO}_{2}$ was established on the basis of at least three of the following criteria: $(a)$ a decrease in $\mathrm{VO}_{2}$ with increasing power output; $(b)$ a respiratory exchange ratio $>1.15$; $(c)$ attainment of age predicted maximal heart rate; $(d)$ a whole blood lactate concentration immediately after exercise of at least $8 \mathrm{mmol} / \mathrm{l}$.

Respiratory variables were measured continuously and averaged every 20 seconds. Exercise heart rate was recorded at five second intervals with a Sports Tester (Polar, Oy, Finland).

\section{Graded exercise test}

Depending on the subject's exercise capacity as estimated by the coach, the initial workload for the graded exercise ranged from 100 tol25 W. The subsequent workload increased by $25 \mathrm{~W}$ every four minutes until it could not be maintained. Capillary blood samples, for ammonia and lactate measurement, were obtained from the fingertip in the last 30 seconds of every step. Extra care was taken to avoid contaminating the blood sample with ammonia from sweat by cleaning the puncture site carefully.

The Ammonia Checker II (Kyoto Daiichi Kagaku Co, Ltd, Kyoto, Japan) was used to measure ammonia in whole blood. The validity and precision of Ammonia Checker II was found to be high. ${ }^{17}$ Lactate in whole blood was analysed enzymatically (Sport 1500; Yellow Springs Instruments, Yellow Springs, Ohio, USA). Average heart rate of the last minute of each step was recorded by the Sports Tester and was calculated as the heart rate for each exercise stage.

The ammonia threshold and lactate threshold were determined by the method of Beaver et al ${ }^{18}$ (fig 1). On the graph of $\log$ [lactate] against $\log \left(\% \mathrm{VO}_{2}\right.$ peak $)$, the data points were divided into two segments by visually selecting the division point (three individuals performed this selection independently). The $\kappa$ coefficient of agreement for lactate threshold and ammonia threshold were $0.569(\mathrm{p}>0.05)$ and $0.535(p>0.05)$ respectively. The division point was selected where the steep portion of the curve began and was assumed to belong to both segments. Using linear regression analysis, two straight lines were used to represent the data points of each segment. Lactate threshold was defined as the intersection between these two lines. A similar threshold was defined as ammonia threshold from data in the graph of log [ammonia] against $\log \left(\% \mathrm{VO}_{2}\right.$ peak). All the threshold values were expressed in terms of $\% \mathrm{VO}_{2}$ peak.

\section{Sprint test}

After the warm up, the participant was asked to work maximally on the Monark 829E for a predetermined time (30 seconds and one minute). During the test, verbal encouragement was continuously provided to ensure maximal effort. Resistance of the ergometer was set to $0.882 \mathrm{~N} / \mathrm{kg}$ body weight and $0.784 \mathrm{~N} / \mathrm{kg}$ body weight for the 30 second and one minute sprint test respectively. All participants performed the 30 second test first and then rested for 15 minutes before performing the one minute test.

Power output was recorded every second during the 30 second and one minute test. The rotation average of three consecutive power output readings was used for further analysis of the data. The maximum power output is defined as the highest power output obtained during the test. The average power output is the average of all the power outputs obtained during the test. The fatigue index, modified from a previous study, ${ }^{19}$ is defined as the difference between the

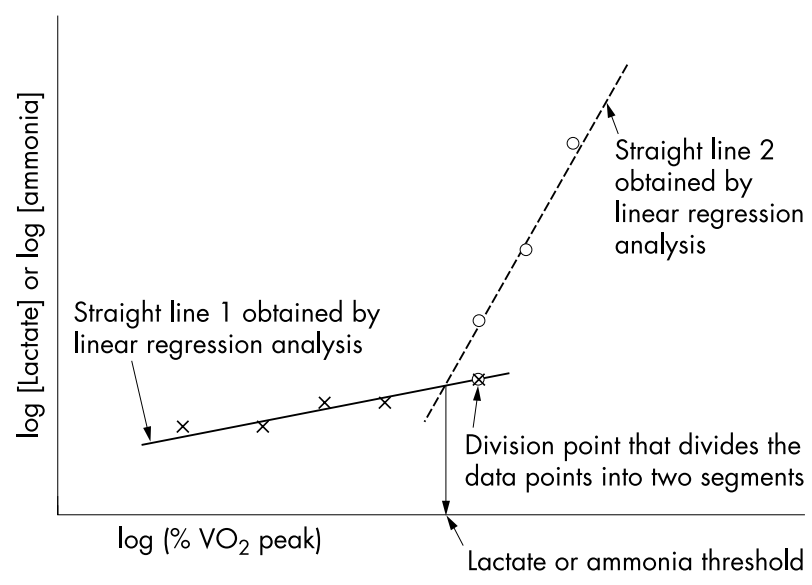

Figure 1 Illustration of the method of identifying the ammonia threshold and the lactate threshold. 
Table 2 Changes in ammonia threshold and other physiological variables during the 12 month study

\begin{tabular}{lllll}
\hline & T1 & T2 & T3 & p Value \\
\hline Ammonia threshold $\left(\%\right.$ peak $\left.\mathrm{VO}_{2}\right)$ & $66.3(5.8)$ & $60.3(6.9)$ & $64.7(4.3)$ & 0.072 \\
Lactate threshold $\left(\%\right.$ peak $\left.\mathrm{VO}_{2}\right)$ & $62.2(5.6)$ & $56.9(7.2)$ & $63.5(4.7)$ & 0.024 \\
Ventilatory threshold $\left(\%\right.$ peak $\left.\mathrm{VO}_{2}\right)$ & $76.0(4.5)$ & $76.0(4.8)$ & $78.6(6.4)$ & 0.313 \\
Peak $\mathrm{VO}_{2}(\mathrm{ml} / \mathrm{min} / \mathrm{kg})$ & $60.6(5.9)$ & $65.9(7.4)$ & $64.6(6.5)$ & $0.000^{*}$ \\
30 s sprint test & & & & \\
Maximum power $(\mathrm{W} / \mathrm{kg})$ & $12.1(1.0)$ & $12.2(1.2)$ & $12.6(1.2)$ & 0.043 \\
Average power $(\mathrm{W} / \mathrm{kg})$ & $10.5(0.7)$ & $10.4(0.9)$ & $10.7(1.2)$ & 0.342 \\
Fatigue index & $0.7(0.1)$ & $0.7(0.1)$ & $0.7(0.0)$ & 0.596 \\
1 min sprint test & & & & \\
Maximum power $(\mathrm{W} / \mathrm{kg})$ & $10.6(1.1)$ & $10.6(0.9)$ & $10.2(0.6)$ & 0.172 \\
Average power $(\mathrm{W} / \mathrm{kg})$ & $7.7(0.8)$ & $8.0(1.0)$ & $8.02(0.8)$ & 0.214 \\
Fatigue index & $0.6(0.1)$ & $0.6(0.1)$ & $0.6(0.1)$ & 0.076 \\
Endurance time $(\mathrm{min})$ & $18.3(4.5)$ & $20.1(5.2)$ & $27.0(6.1)$ & $0.000^{*}$ \\
\hline
\end{tabular}

Values are mean (SD). $p$ Value was obtained by univariate repeated measures analysis of variance

*Significant difference in terms of time $(p<0.005)$.

maximum power and the minimum power divided by maximum power.

\section{Endurance test}

The ventilatory threshold as obtained from the peak $\mathrm{VO}_{2}$ test is used as the workload in the endurance test. The ventilatory threshold was identified by three independent testers when at least two of the following criteria were satisfied: (a) a systematic increase in the ventilatory equivalent for oxygen $\left(\mathrm{VEO}_{2}\right)$ without a corresponding increase in ventilatory equivalent for carbon dioxide $\left(\mathrm{VeCO}_{2}\right) ;(b)$ the rate of carbon dioxide production $\left(\mathrm{VCO}_{2}\right)$ is larger than the rate of oxygen consumption $\left(\mathrm{VO}_{2}\right) ;(c)$ non-linear increase in ventilation. The $\kappa$ coefficient of agreement for the ventilatory threshold was $0.724(\mathrm{p}>0.05)$.

After the warm up, the participant exercised at the ventilatory threshold as obtained from the peak $V_{O_{2}}$ test. The test was terminated when the participant could not maintain the workload. The endurance time is defined as the duration of the test in minutes.

\section{Statistical analysis}

All data are presented as mean (SD). Test scores were analysed by multivariate repeated measures analysis of variance with $\alpha$ set at 0.05 . In the event of finding significant differences, univariate repeated measures analysis of variance was conducted for each dependent variable. Bonferroni correction was considered in these tests, and $\alpha$ was set at 0.005 . The Pearson correlation coefficient between ammonia threshold and various physiological measurements, including lactate threshold, ventilatory threshold, peak $\mathrm{Vo}_{2}$, and sprinting capacity related variables, was also calculated. Again Bonferroni correction was considered, and the significant concentration was set at $\mathrm{p}<0.005$.

The intraclass correlation coefficients were calculated to represent the intertester agreements in the identification of the thresholds (ammonia, lactate, and ventilatory).

\section{RESULTS}

Table 2 lists the measured ammonia threshold and other physiological variables at the three test points. Peak $\mathrm{VO}_{2}$ and endurance time were significantly different at the different test times. Ammonia threshold, lactate threshold, ventilatory threshold, and all sprint related measurements were not significantly changed across the three tests. The intraclass correlation coefficients were $0.781(p=0.007), 0.802$ $(\mathrm{p}=0.006)$, and $0.845(\mathrm{p}=0.006)$ for ammonia threshold, lactate threshold, and ventilatory threshold respectively.

Peak $\mathrm{VO}_{2}$ increased by $8.8 \%$ and $6.6 \%$, from the first test (60.56 (5.9) $\mathrm{ml} / \mathrm{min} / \mathrm{kg}$ ), to the second (65.91 (7.4) $\mathrm{ml} / \mathrm{min} /$ $\mathrm{kg})$ and the third test $(64.55(6.5) \mathrm{ml} / \mathrm{min} / \mathrm{kg})$ respectively. Endurance time increased by $9.3 \%$ and $47.2 \%$, from the first test (18.34 (4.53) $\mathrm{min})$, to the second (20.05 (5.23) $\mathrm{min}$ ) and the third test $(27.00(6.06) \mathrm{min})$ respectively.

Resting lactate and ammonia concentrations obtained before the step test at the three time points were: Tl, 1.4 (0.3) mM, 40.5 (5.8) $\mu \mathrm{M}$; T2, 1.3 (0.3) mM, 34.6 (6.4) $\mu \mathrm{M}$; T3, 1.1 (0.3) $\mathrm{mM}, 42.6$ (8.2) $\mu \mathrm{M}$ respectively. Maximum lactate and ammonia concentrations obtained at the last stage of the step test at the three time points were: Tl, 8.3 (1.8) mM, 98.6 (25.5) $\mu \mathrm{M} ; \mathrm{T} 2,9.7$ (2.4) $\mathrm{mM}, 130.6$ (17.0) $\mu \mathrm{M}$; T3, 6.3 (1.7) mM, 101.6 (31.6) $\mu \mathrm{M}$ respectively.

Table 3 lists the Pearson correlation coefficients between ammonia threshold and the various physiological measurements. When $\alpha$ is set at 0.005 , significant correlation is found between the ammonia threshold and endurance time $(r=0.915, \mathrm{p}=0.001)$ only.

\section{DISCUSSION}

This is the first study on the effect of long term training (one year) on ammonia threshold. The subjects were adolescents whose ammonia response to training may differ from that of adults. Previous studies have found that children have a lower ammonia response during maximal exercise. ${ }^{10}$ This one year training programme emphasised the general development of the cyclists, and there were no major competitions to peak for. It consisted of a balance between aerobic, anaerobic, and musculoskeletal training. This training programme induced a significant increase in both peak $\mathrm{VO}_{2}$ and endurance time at ventilatory threshold. However, the sprint related measurements showed no significant differences across the three tests. Neither were the ammonia, lactate, and ventilatory thresholds modified significantly by

Table 3 Correlation of ammonia threshold with various physiological measurements obtained on the first test ( $\mathrm{n}=8$ )

\begin{tabular}{lll}
\hline Physiological measurement & $\boldsymbol{r}$ Value & $\mathbf{p ~ V a l u e ~}$ \\
\hline Peak oxygen uptake $(\mathrm{ml} / \mathrm{kg} / \mathrm{min})$ & -0.404 & 0.320 \\
Lactate threshold $(\%$ peak $\mathrm{Vo})$ & 0.674 & 0.067 \\
Maximum power of $30 \mathrm{~s}(\mathrm{~W} / \mathrm{kg})$ & -0.202 & 0.631 \\
Average power of $30 \mathrm{~s}(\mathrm{~W} / \mathrm{kg})$ & -0.276 & 0.508 \\
Fatigue index of $30 \mathrm{~s} \mathrm{test}$ & -0.656 & 0.078 \\
Maximum power of $1 \mathrm{~min}(\mathrm{~W} / \mathrm{kg})$ & -0.286 & 0.492 \\
Average power of $1 \mathrm{~min}(\mathrm{~W} / \mathrm{kg})$ & -0.708 & 0.049 \\
Fatigue index of $1 \mathrm{~min}$ test & -0.037 & 0.930 \\
Ventilatory threshold $\left(\%\right.$ peak $\left.\mathrm{Vo}_{2}\right)$ & 0.572 & 0.139 \\
Endurance time $(\mathrm{min})$ & $0.915^{*}$ & 0.001 \\
\hline
\end{tabular}

*Significant correlation with ammonia threshold $(p<0.005)$. 


\section{Take home message}

Ammonia threshold is a measure of the ability to sustain submaximal exercise. However, it is not sensitive enough to pick up the improvement in exercise ability that is expected from a non-specific one year training programme.

the programme. The training programme is therefore able to improve aerobic capacity and endurance at the submaximal workload of the cyclists. It did not improve sprinting ability and the thresholds. It should be noted that the effect of this one year programme is very different from that of a relatively short endurance training programme. For instance, a 20 week endurance training programme induced a significant increase in peak $\mathrm{VO}_{2}$ and anaerobic threshold, ${ }^{7}$ but our long lasting and relatively non-specific programme only improved peak $\mathrm{VO}_{2}$ and not the thresholds.

Consistent with previous studies on the ammonia response to graded exercise, ${ }^{215}$ we observed a curvilinear relation between exercise intensity and blood ammonia. Blood ammonia remained near resting concentration during mild exercise and increased exponentially at workloads above the ammonia threshold. At low workloads, slow twitch oxidative fibres are mainly used, which are low in AMP deaminase. ${ }^{20}$ The rate of ammonia production is therefore limited. At higher workloads, more fast twitch fibres are recruited. ${ }^{20}$ Activation of the AMP deaminase in the fast twitch fibres results in large amounts of ammonia being produced.

A previous study reported that, after a short term endurance training programme (8-12 sessions, one hour per session at $\left.60-90 \% \mathrm{VO}_{2} \mathrm{MAX}\right)$, the ammonia response after 45 minutes of exercise at $80 \% \quad \mathrm{VO}_{2} \mathrm{MAX}$ was significantly reduced. ${ }^{7}$ However, the ammonia response, in relation to the $\% \mathrm{VO}_{2} \mathrm{MAX}$, during a progressive exercise protocol, did not change after training. In another study by Lo and Dudley, ${ }^{8}$ seven weeks of intensive training, which increased $\mathrm{VO}_{2} \mathrm{MAX}$ by $32 \%$, modified the ammonia response to graded exercise by lowering the blood ammonia concentration at the same absolute power and not for that at the similar relative intensity. However, neither study ${ }^{7}$ investigated the effect of the training programme on the ammonia threshold in graded exercise. In our long term training programme, the peak $\mathrm{VO}_{2}$ was increased by only $8.8 \%$ and $6.6 \%$, from the first test, to the second and third tests respectively. Our results seem to be consistent with previous reports that training does not modify ammonia response, at the same relative intensity, during graded exercise. The ammonia threshold obtained from the four minute step graded exercise did not differ significantly at the three test times.

The subjects in our study were not fully grown adults; their mean (SD) age was 16.1 (1.0) at the start. Previous studies $^{13} 14$ have shown that the maximal anaerobic power and capacity of children is less developed than that of adults. The rates of glycogen utilisation and lactate production during maximal exercise in children are lower than those in adults. ${ }^{11}$ The activity of muscle phosphofructokinase, the rate limiting enzyme in glycolysis, has been found to be proportional to age. ${ }^{21}$ The increase in ammonia after maximal exercise is also less profound in children than in adults. ${ }^{10}$ However, we found no differences in ammonia threshold obtained before, mid-way, and after the one year training programme.

Although both endurance training ${ }^{7} 822$ and sprint training ${ }^{9}$ have been shown to be effective in modifying ammonia response during exercise, all of these studies were performed on adults. The effect of training on the ammonia response in children has not been studied directly. Nazar et $a l^{10}$ found that the ammonia response of trained peripubertal boys and girls was larger than that of untrained counterparts at the same intensity. This is the only reported study to indirectly investigate the possible effect of training on ammonia response in children. The findings need confirmation from direct studies on the effect of training. Will the underdeveloped ammonia production system of children be responsive to training? In our study, the ammonia threshold, obtained from the four minute step graded exercise, was not significantly different across the time points. However, the training programme was only effective in modifying peak $\mathrm{VO}_{2}$ and endurance time, and the same results may not be obtained with a training programme that is more intense or more specifically designed to improve endurance or sprinting performance.

A significant correlation was found between ammonia threshold and endurance time. None of the other physiological variables investigated correlated significantly with ammonia threshold. This is similar to findings obtained with a group of relatively untrained adults. ${ }^{16}$ In that study, a significant correlation with ammonia threshold was found for both endurance time and lactate threshold. This discrepancy between the two groups of subjects seems to support the suggestion that the often observed correlation between ammonia and lactate concentration is phenomenological and not causative. ${ }^{23}$ However, there are studies that suggest that exercise ammonia and lactate concentrations are linked. ${ }^{24}$

No significant correlation was found between ammonia threshold and the measurements related to anaerobic power and capacity ( 30 seconds and one minute maximum test). Similarly, no significant correlation was found between ammonia threshold and peak $\mathrm{VO}_{2}$. These findings suggest that ammonia threshold is not a measure of anaerobic power, anaerobic capacity, and aerobic capacity. As endurance time is a measure of the ability to sustain submaximal exercise, the consistent correlation between ammonia threshold and endurance time in both groups of subjects (our present and previous ${ }^{16}$ studies) further confirms that ammonia threshold is a measure of the ability to sustain submaximal exercise.

\section{CONCLUSIONS}

This study is noteworthy in three aspects. Firstly, it is the first investigation of the effect of one year of non-specific training on the ammonia response to exercise. Secondly, it is the first time that the effect of training on a group of children has been directly examined. Thirdly, the effect of training on ammonia threshold has not previously been thoroughly addressed. The one year training programme was found to be ineffective in inducing any significant change in the ammonia threshold in this group of junior cyclists. Correlation between ammonia threshold and endurance time was significant. This reconfirms that ammonia threshold is a measure of the ability to sustain submaximal exercise.

\section{Authors' affiliations}

Y Yuan, Hong Kong Sports Development Board, Sports Institute, Shatin, Hong Kong

K-M Chan, Chinese University of Hong Kong

\section{REFERENCES}

1 Babij P, Matthews SM, Rennie MJ. Changes in blood ammonia, lactate and amino acids in relation to workload during bicycle ergometer exercise in man. Eur J Appl Physiol 1983;50:405-11.

2 Banister EW, Allen ME, Mekjavic IB, et al. The time course of ammonia and lactate accumulation in blood during bicycle exercise. Eur J Appl Physiol 1983;51:195-202.

3 Maclean DA, Spriet LL, Hultman E, et al. Plasma and muscle amino acid and ammonia responses during prolonged exercise in humans. J Appl Physiol 1991;70:2095-103. 
4 Broberg S Sahlin K. Adenine nucleotide degradation in human skeletal muscle during prolonged exercise. J Appl Physiol 1989;67:116-22.

5 Mutch BJC, Banister EW. Ammonia metabolism in exercise and fatigue: a review. Med Sci Sports Exerc 1983;15:41-50.

6 Saltin B, Kim CK, Terrados N, et al. Morphology, enzyme activities and buffer capacity in leg muscles of Kenyan and Scandinavian runners. Scand J Med Sci Sports 1995;5:222-30.

7 Denis C, Linossier MT, Dormois D, et al. Effects of endurance training on hyperammonaemia during 45-min constant exercise intensity. Eur J Appl Physiol 1989;59:268-72.

8 Lo PY, Dudley GA. Endurance training reduces the magnitude of exerciseinduced hyperammonemia in humans. J Appl Physiol 1987;62:1227-30.

9 Snow RJ, McKenna MJ, Carey MF, et al. Sprint training attenuates plasma ammonia accumulation following maximal exercise. Acta Physiol Scand 1992;144:395-6

10 Nazar K, Dobrzynski B, Lewicki R. Relationship between plasma ammonia and blood lactate concentrations after maximal treadmill exercise in circumpubertal girls and boys. Eur J Appl Physiol 1992;65:246-50.

11 Ericsson BO. Muscle metabolism in children: a review. Acta Paediatr Scand 1980;238(suppl):1-27.

12 Maćek M, Vávra J, Benesová $H$, et al. The adjustment of oxygen uptake at the onset of exercise: relation to age and work load. In: Ilmarinen J, Välimäki I, eds. Children and sport. Berlin, Heidelberg, New York: Springer-Verlag, 1984: 129-35.

13 Blimkie CJ, Roache P, Hay JT, et al. Anaerobic power of arms in teenage boys and girls: relationship to lean tissue. Eur J Appl Physiol Occup Physiol 1988:57:677-83.

14 Vandewalle H, Peres G, Sourabie B, et al. Force-velocity relationship and maximal anaerobic power during cranking exercise in young swimmers. Int J Sports Med 1989;10:439-45.
15 Buono MJ, Clancy TR, Cook JR. Blood lactate and ammonia ion accumulation during exercise using a log-log transformation. J Appl Physiol 1984;60:472-8

16 Yuan Y, So R, Wong S, et al. Ammonia threshold: comparison to lactate threshold, correlation to other physiological parameters and response to training. Scand J Med Sci Sports 2002;12:358-64.

17 Huizenga JR, Gips CH. Determination of blood ammonia using the Ammonia Checker. Ann Clin Biochem 1983;20:187-9.

18 Beaver WL, Wasermann K, Whipp B. Improved detection of lactic threshold during exercise using a log-log transformation. J Appl Physiol 1986;60:472-8

19 Bogdanis GC, Nevill ME, Boobis LH, et al. Recovery of power output and muscle metabolites following $30 \mathrm{~s}$ of maximal sprint cycling in man. J Physiol 1995:482:467-80.

20 Gollnick PD, Sembrowich WL. Adaptations in human skeletal muscle as a result of training. In: Amsterdam EA, Wilmore JH, DeMaria AN, eds. Exercise in cardiovascular health and disease. New York: Yorke Medical, 1977:70-94.

21 Ericsson BO, Saltin B. Muscle metabolism during exercise in boys aged 11 to 16 years compared to adults. Acta Paediatr Belg 1974;28(suppl):257-65.

22 Dudley GA, Terjung RL. Influence of aerobic metabolism on IMP accumulation in fast-twitch muscle. Am J Physiol 1985;248:C37-42.

23 Teriung RL, Tullson PC. Ammonia metabolism during exercise. In: Lamb DR, Gisolfi CV, eds. Energy metabolism in exercise and sport. Dubuque, IA: Brown \& Benchmark, 1992:235-68.

24 Itoh H, Ohkuwa T. Ammonia and lactate in the blood after short-term sprint exercise. Eur J Appl Physiol 1991;62:22-5.

25 Pollock ML, Schmidt DH, Jackson AS. Measurement of cardiorespiratory fitness and body composition in the clinical setting. Compr Ther 1980;6:12-27. 